\title{
ESTADO, EDUCACIÓN Y POBREZA: NUEVAS VINCULACIONES A PARTIR DE LAS POLÍTICAS PÚBLICAS FOCALIZADAS
}

\author{
Carmen B. Godino Morales*
}

RESUMEN

El tema central del trabajo gira alrededor de las llamadas políticas públicas focalizadas que comenzaron a emerger en la Argentina como alternativa de acción frente a las grandes desigualdades sociales producidas por la aplicación de políticas neoliberales. El concepto de pobreza, en este artículo está implícito en una gran parte de esas políticas públicas.

PALABRAS CLAVE: NEOLIBERALISMO $*$ ESTADO $*$ POLÍTICAS PÚBLICAS $*$ EDUCACIÓN * POLÍTICAS FOCALIZADAS $*$ POBREZA

\section{ABSTRACT}

This paper deals with the so called public focused policies which arose in Argentina as an answer to the high social cost produced by the application of neoliberal policies. The concept of poverty, as it will be shown, is essential that most public policies justify their existence on trying to solve it.

KEY WORDS: NEOLIBERALISM $*$ STATE $*$ PUBLIC POLICIES $*$ EDUCATION $*$ FOCUSED POLICIES * POVERTY

\section{INTRODUCCIÓN}

En este trabajo se aborda el tema de la paulatina retirada del Estado - específicamente desde la última década del siglo XX - con las estrategias desplegadas, manifiestas principalmente en lo que se ha denominado políticas públicas.

Se presenta en primer lugar, las características generales del modelo intervencionista gestado en la década del treinta en la Argentina.
A partir de esta explicación teórica se realiza un análisis de la conformación actual de un nuevo modelo de intervención: "el modelo de intervención del mercado".

Frente a lo descrito, además, se realiza una delineación del concepto de pobreza haciendo hincapié en la complejidad del término y situándolo como uno de los puntos centrales sobre los cuales versan las políticas públicas en la Argentina. Con base a este panorama se estudiará específicamente el escenario de las políticas

*_Instituto de Formación Docente, San Luis, Argentina. belen_godino@yahoo.com.ar 
públicas focalizadas explicando el surgimiento y características de las mismas.

Por último, para ilustrar este panorama político-social-económico se desglosa específicamente una política educativa focalizada: $E l$ Programa Nacional de alfabetización y educación básica para jóvenes y adultos, el cual es una iniciativa del Ministerio de Educación, Ciencia y Tecnología a partir del 2004. Se presenta este ejemplo para comprender aún más el complejo escenario que se vive en el país y la dificultad de estos planes para alcanzar los objetivos propuestos.

Se pretende, a partir de lo planteado en el trabajo, abrir ciertas líneas de pensamiento que den cuenta de la difícil situación socio-políticaeconómica que sufre la Argentina desde hace ya varias décadas y analizar bajo este contexto las acciones que se proponen desde las políticas públicas.

\section{NUEVOS PARADIGMAS POLÍTICOS}

Los paradigmas actuales sobre las finanzas públicas surgen de los programas de ajuste y "reforma estructural" que se han venido aplicando en la región latinoamericana después de la crisis de la deuda externa de 1982, y tienen como principio ideológico la vigencia del mercado y el desmonte del intervencionismo estatal. El diseño de estos programas ha estado fuertemente influido por los organismos financieros internacionales, en especial el Fondo Monetario Internacional (FMI), el Banco Mundial (BM) y el Banco Interamericano de Desarrollo (BID), Giraldo, 2001.

Las reformas estructurales que se han venido introduciendo en la región hacen referencia a remover todas las estructuras que obstaculizan el libre funcionamiento de los mercados. En este sentido, las reformas tienen dos dimensiones. La primera corresponde a disminuir la intervención del Estado para dejar un mayor juego al mercado, $y$ cuando esta intervención sea indispensable debe realizarse con los criterios e instrumentos más cercanos a los que emplearía el mercado. En la segunda, las reformas al Estado están acompañadas con reformas a los mercados para que estos actúen de manera más libre, sin las distorsiones que introducen los controles y la intervención estatal. Este segundo punto es lo que se conoce como flexibilización, la cual se expresa en el mercado de bienes con la apertura comercial, en el de capitales, con la desregulación financiera y en el laboral, con la flexibilización laboral (Giraldo, 2001).

Esta última no se reduce a la necesidad de ajustarse mecánicamente a una tarea puntual, sino que exige que el operador esté de inmediato disponible para responder a las fluctuaciones de la demanda. La gestión en flujo continuo, la producción sobre pedido, la respuesta inmediata a las coyunturas del mercado, se convierten en los imperativos categóricos del funcionamiento de las empresas competitivas (Castel, 1997).

\section{REMONTÁNDONOS AL VIEJO PARADIGMA: EL PARADIGMA DE INTERVENCIÓN}

En primer lugar, hay que distinguir entre lo que se conoce como Estado de Bienestar y Estado Keynesiano.

El intervencionismo surge con el Estado de Bienestar a fines del siglo XIX y fue una respuesta de carácter sociopolítico; en tanto, lo que se conoce como Estado Keynesiano tiene origen en determinantes económicos y se conforma para dar respuesta a la crisis de los años treinta en los países del centro.

El Estado de Bienestar surge como iniciativa del canciller Otto Von Bismarck a fines del siglo XIX, con la creación del seguro social, el cual se basaba en reglas no discriminatorias, relativamente automáticas, dirigido al asalariado, más que al pobre o al miserable (Giraldo, 2001). Este Estado surgió, de una parte, por la necesidad de mantener un orden social, como reacción al movimiento obrero en su condición de actor social y político; $y$ de otra, por la necesidad de legitimación y apoyo político en virtud de la extensión del sufragio universal y la competencia política (Giraldo, 2001).

En América Latina, específicamente se desplegó aún más el modelo de intervención, en los años treinta, luego de la crisis de la bolsa, debido a la implementación de la política de sustitución de importaciones.

A comienzos de la década del ochenta se le atribuye mayor importancia a las importaciones $y$ 
exportaciones debido a la decadencia del modelo intervencionista procedente de la década del treinta. Tal como lo afirman los documentos del Banco Mundial (1991) "El mercado interno no sólo se agota por dejar de ser una fuente de expansión económica sino que además hay que reconocer el hecho de que la economía mundial se ha globalizado" (Giraldo, 2001: 15).

Dentro de este panorama de "economía de intervención" por parte del Estado, se deduce que este puede realizar varias acciones. A continuación se mencionan aquellas acciones que se relacionan con el tema del presente trabajo.

En primer lugar, cuando el Estado debe intervenir en la provisión de bienes y servicios públicos, se trata de que realice dicha intervención dentro de la racionalidad del mercado. Esta racionalidad consiste en que la provisión de bienes y servicios estatales se debe hacer a través del mercado: los servicios deben ser vendidos en un mercado. Esto es lo que lleva a eliminar los subsidios a la oferta y al establecimiento de los subsidios a la demanda. Lo primero significa restringir el financiamiento estatal a las entidades públicas, para que estas se financien a través del mercado mediante la venta de bienes y servicios. $\mathrm{Al}$ introducir los subsidios a la demanda, se trata de que los recursos estatales vayan directamente a los usuarios pobres, para que mediante el subsidio paguen la atención del servicio. Esto es lo que se entiende por focalización (Giraldo, 2001).

En segundo lugar, tal como se viene mencionando, lo público deja de ser monopolio del Estado y puede ser atendido por entes diferentes a los estatales. Como dice el BID (1998) "Otra forma de multiplicar los escasos recursos públicos es construir asociaciones, con grupos comunitarios, ONG, organizaciones religiosas, organismos existentes de servicios sociales y el sector privado" (Giraldo, 2001: 20).

\section{DESTINATARIOS DE LOS SUBSIDIOS \\ A LA DEMANDA: LOS POBRES}

Otro de los conceptos que se retoma en este análisis es el de pobreza. En general, las diferentes posiciones reconocen que la pobreza se identifica con la idea de "privación", de "ausencia", de "carencia". Sin embargo, existen desacuerdos cuando se pretende precisar cuáles son los elementos que autorizan a identificar un determinado estado de situación como de pobreza. Otro campo de desacuerdo es aquel que distingue entre la mera posesión de esos elementos y las efectivas posibilidades y aptitudes para hacer uso conveniente de ellos. También se observan disputas en cuanto a la privación de unos y la posesión de otros, entre ausencias $y$ presencias, entre carencias y abundancias (Lo Vuolo y otros, 1997).

Entre otras características, los estudios sobre la pobreza concluyen que el concepto tiene carácter multidimensional, reconoce gradaciones $y$ no puede definirse en abstracto sino que requiere ser situado. El carácter multidimensional advierte que la privación no se restringe a un único elemento sino a un sistema relacionado de elementos. Las gradaciones reflejan que la privación de los elementos que definen la pobreza no es la misma para todas las dimensiones sino que puede identificarse la presencia de "una banda", de una "dispersión" para todas y cada una de ellas. Finalmente, decir que la pobreza requiere ser situada, significa admitir que reconoce coordenadas de tiempo y espacio. Una persona no "es" pobre sino que "vive" (nace, muere) en situación de pobreza (Lo Vuolo y otros, 1997).

Las políticas, aplicadas por el Estado en América Latina, cuyos destinatarios son los pobres, no tienen como objetivo la erradicación o la lucha contra este problema social, sino por el contrario, lo que persiguen es la paulatina mantención de ciertos índices de población indigente para sustentar así el despliegue de planes y programas destinados a dicho sector social.

Lo Vuolo y Barbeito (1997) nos presentan tres visiones de la pobreza:

$\diamond$ La visión modernista-tecnocrática. Se construye mezclando un lenguaje a la vez "médico" y "bélico": la pobreza se entiende como una enfermedad contra la cual hay que luchar para erradicarla para que no infecte al cuerpo social sano.

$\diamond$ La visión asistencial-represiva. Aquí la pobreza se ve como un peligro social y político del cual habría que ocuparse mediante la asistencia, la reeducación y la 
represión. En cierta forma, también aquí se atribuye al pobre la falta de previsión $y$ de emprendimiento, lo cual deriva en la acusación de cierta inmoralidad por haber llegado a esa situación.

La visión caritativa. Entiende que la pobreza es inaceptable en sí misma desde un fundamento ético y reclama solidaridad hacia los afectados. Esta visión desnaturaliza la idea de derechos sociales y ciudadanos, en beneficio de una ética personal entre el donante $y$ el receptor, que en general es mediada por una organización. La caridad se ejerce a través de organizaciones que se especializan en esa actividad y justifican su existencia por ella. La permanencia de la visión caritativa, por otro lado, se sostiene en la idea de "participación" motorizada por las llamadas "organizaciones no gubernamentales" (ONGs) y esta participación se promueve como "movilización económica" mediante el tipo de propuestas del tipo de "economía solidaria" o "economía popular".

\section{POLÍTICAS FOCALIZADAS}

Con base en la explicación anterior de la pobreza se presenta una descripción detallada de lo que se entiende por políticas focalizadas, ya que a partir de las mismas, se está "focalizando" específicamente en la población denominada "pobre".

La focalización consiste en dirigir el gasto público (los subsidios) hacia las personas que lo necesitan: los pobres. Es una herramienta dirigida a atender eficazmente situaciones de exclusión, así como a los grupos poblacionales directamente afectados. Entonces, la focalización se inscribe como política de carácter más selectivo (Giraldo, 2001).

Bajo esta perspectiva, es importante rescatar el concepto de vulnerabilidad social, (Giraldo, 2001), el cual hace referencia a individuos, hogares, regímenes o grupos afectados por situaciones o procesos que llevan a la imposibilidad de acceder a bienes, recursos o capacidades socialmente disponibles. Este sector de vulnerabilidad social estará integrado por todos aquellos sujetos que no puedan desplegar en su realidad la satisfacción de sus derechos. Entre uno de los derechos fundamentales que posee la persona está el derecho a la educación en sus máximas expresiones, el cual bajo la mirada del mercado, se ha convertido, como se verá más adelante, en un servicio más que se adquiere en el mismo.

Asociado al concepto de vulnerabilidad social está el de necesidades básicas insatisfechas (NBI). El mismo hace referencia a la incensibilidad a bienes y servicios básicos, como mínimos en educación, salud, servicios públicos domiciliarios. Esta inaccesibilidad significa analfabetismo, precariedad en la salud, vivienda inadecuada, no acceso a servicios públicos elementales (Giraldo, 2001).

Frente a lo mencionado hasta el momento, es relevante plantear que en la sociedad actual, a partir de la primacía de la lógica del mercado, la educación es vista como uno de los servicios que ofrece el mismo, ya que los Organismos Internacionales manifiestan:

La educación determina la productividad de la fuerza de trabajo que interviene en cualquier función de producción, por lo tanto, es presentada en términos de productividad económica, la cual a la postre se traduce en remuneración individual en el mercado. En este sentido, la educación se convierte en un bien privado que debe ser adquirido a través del mercado (Giraldo, 2001).

\section{UN EJEMPLO DE POLÍTICA EDUCATIVA FOCALIZADA}

En el campo de la educación se describen brevemente los lineamientos generales del Programa Nacional de Alfabetización y Educación Básica para Jóvenes y Adultos impulsado por el Ministerio de Educación, Ciencia y Tecnología. Se estima que este Programa quedaría encuadrado dentro de lo que se denomina políticas focalizadas, ya que el mismo está destinado focalmente a aquellas personas que no han podido acceder al sistema educativo $y$, por lo tanto, no acreditan la adquisición de la lectoescritura y el cálculo. Lo que se remarca de esta iniciativa del Ministerio es que, 
como se había mencionado anteriormente, dirige el gasto público (los subsidios) hacia las personas que lo necesitan: en este caso los llamados analfabetos totales ${ }^{1}$.

\section{CARACTERÍSTICAS GENERALES DEL PROGRAMA}

Esta iniciativa se desarrolla en el marco de la Década de la Alfabetización 2003-2012 declarada por las Naciones Unidas y sienta sus bases en el concepto de "sociedad educadora".

\section{OBJETIVOS}

$\diamond$ Reducir al 50\% los índices actuales de analfabetismo en la población de 15 años y más.

$\diamond$ Favorecer la continuidad en la escolaridad básica de los jóvenes y adultos.

$\diamond$ Promover la participación ciudadana y el compromiso social de jóvenes $y$ adultos alfabetizados.

$\diamond$ Fortalecer el desarrollo de articulaciones interinstitucionales que representen un aporte a la superación de la fragmentación social existente en nuestro país.

\section{IMPLEMENTACIÓN}

Se desarrolla en dos instancias consecutivas: alfabetización inicial o introductoria de cinco meses de duración y articulación con el sistema de educación de jóvenes y adultos con el objeto de completar la escolaridad básica.

\section{¿QUIÉNES Y DÓNDE?}

El Programa está destinado a jóvenes y adultos analfabetos de 15 años y más, incluyen-

1 Es analfabeta pura o total aquella persona que no puede leer y escribir los textos necesarios para desempeñarse en los diferentes ámbitos de la sociedad. Se dice que no ha adquirido los conocimientos de lectoescritura y cálculo. do a la población de los establecimientos penitenciarios. Las actividades se desarrollan en los Centros de Alfabetización que funcionan en espacios de organizaciones de la sociedad civil, tales como iglesias, centros de salud, gremios, entre otros. También en escuelas o centros educativos de jóvenes y adultos.

\section{PARTICIPACIÓN DEL VOLUNTARIADO SOCIAL}

Los alfabetizadores son voluntarios (docentes, estudiantes universitarios, integrantes de organizaciones de la sociedad civil, sindicatos, agrupaciones barriales, organismos religiosos, alumnos de institutos de formación docente, entre otros). Dada la importancia de mantener relaciones horizontales que contemplen las características del desarrollo local y la necesidad de estimular valores solidarios en los y las jóvenes y en la población en general se utiliza un modelo de sociedad educadora.

\section{ARTICULACIÓN CON LA EDUCACIÓN BÁSICA DE JÓVENES Y ADULTOS}

A mediano plazo, el propósito del Programa es favorecer y acompañar la inclusión en las instituciones de la Educación Básica de Jóvenes $y$ Adultos de las personas recientemente alfabetizadas, con el objeto de que completen su escolaridad.

\section{¿CON QUIÉNES?}

El Ministerio de Educación, Ciencia y Tecnología acuerda los mecanismos de implementación del Programa, con las autoridades educativas provinciales y del Gobierno de la Ciudad de Buenos Aires, a través de la firma de convenios. Organizaciones de la Sociedad Civil (ocss), tales como sindicatos, organizaciones estudiantiles $y$ otras, $y$ Organizaciones No Gubernamentales (ONGs) articulan con cada jurisdicción estableciendo convenios intersectoriales con organizaciones estatales en sumarse al desarrollo del Programa. 
VINCULACIÓN CON EL TRABAJO

Y LA FORMACIÓN PROFESIONAL

El Programa prevé instancias de vinculación con el mundo del trabajo a través de las cuales las personas que participen en sus acciones estarán en condiciones de formarse en un oficio, mejorar $y$ actualizar sus conocimientos sobre un área laboral y articular la formación general (básica) con la formación para el trabajo.

\section{LOS MATERIALES}

El Ministerio de Educación, Ciencia y Tecnología entrega materiales a alfabetizadores $y$ alumnos. Los primeros están compuestos por un libro para el alfabetizador; Orientaciones para su trabajo; 40 vídeos complementarios del material impreso realizados por Eduardo Mignona; 25 láminas ilustradas por el dibujante Roberto Fontanarrosa y un bolso para los materiales. Los materiales para los alumnos incluyen lápices, goma, cuaderno, tijera, goma de pegar, regla y un set de letras, sílabas y números. Los alfabetizadores también reciben un importe para gastos de movilidad $y$ seguro contra riesgos de trabajo.

Teniendo en cuenta los conceptos expuestos a lo largo del trabajo se presentan a continuación algunos puntos fundamentales que orientan el análisis del Programa de Alfabetización. Ellos son:

$\diamond$ La no incorporación inmediata del sujeto "analfabeto" al sistema educativo, ya que el Programa es un "curso de alfabetización inicial", que no está inserto en la estructura misma del Sistema Educativo Nacional. Todavía no se han presentado las gestiones pertinentes que admitan que los alumnos pertenecientes al Programa continúen con sus estudios básicos. Cabe recordar que este curso se presenta como una alternativa de educación para adultos (para aquellos que no estén en el sistema) paralelamente al dictado de las clases en las correspondientes escuelas destinadas para esta población. No se realizó un estudio previo por provincias discriminando la oferta educativa que cada una presenta en materia de educación de adultos. Indistintamente que existan o no escuelas para ellos, este curso se disipa por todo el país. A modo de ejemplo, cabe aclarar, que en la provincia de San Luis no existen escuelas de formación básica (lo que se llama EGB 1 y EGB 2) para adultos que no hayan culminado su escolaridad primaria. Por lo tanto, este Programa se convierte en la única posibilidad de acceso a la educación que, al menos en la actualidad, tienen los adultos denominados analfabetos totales.

$\diamond$ El Programa puede ser gestionado por personas que no posean la formación profesional idónea para asumir el despliegue de los procesos de enseñanza y de aprendizaje específicamente para la población adulta. Esta misma es una población que por diferentes motivos no ha podido asistir a la institución educativa o que tal vez asistió, pero no adquirió los conocimientos de la lectoescritura y el cálculo. Por lo tanto, se necesita acreditar mínimamente conocimientos que provengan del campo de la Filosofía de la Educación, de la Sociología, la Psicología, la Didáctica, entre otros. Esto se traduce en el conocimiento de estrategias de manejo de grupo, de cómo aprende un adulto y cómo se le enseña, el para qué de la enseñanza, los fines de la educación. Si descuidamos en darle un lugar a estos postulados estaríamos dedicando sólo un lugar a un aspecto técnico-mecánico: "este es el manual de instrucción en donde están detalladas las tareas y cualquiera que tenga voluntad puede hacerlo". Con lo expuesto se quiere volver a uno de los objetivos que presenta el Programa: la disminución del analfabetismo. Cabría hacerse la siguiente pregunta ¿Realmente el Programa fue diseñado para cumplir este objetivo? O como se mencionaba anteriormente con respecto a las políticas sociales, ¿Logran revertir problemas como el analfabetismo? O quizá, no fueron diseñadas para alcanzar dicho objetivo.

$\diamond$ Otro de los puntos a discutir es la gran inversión del Programa en cuanto a materiales educativos (vídeos, láminas, 
cuadernos, fichas) en contraposición con un reducido presupuesto para el alfabetizador (seguro de vida $y$ gastos de movilidad). Esto puede inferirse, retomando a Lo Vuolo y Barbeito, en que sigue existiendo una fuerte visión asistencial y caritativa del analfabeto. Lo asistencial porque de alguna manera se puede estar visualizando a los analfabetos como un peligro político del país en cuanto a su productividad; $y$ caritativa porque reclama solidaridad hacia los afectados recurriendo al voluntariado.

$\diamond \mathrm{El}$ aspecto del voluntariado es un tema central. La utilización de un mecanismo legal (Ley del Voluntariado) como recurso para el cumplimiento de la tarea de la alfabetización es una estrategia que se inscribe dentro de la lógica del mercado. Dentro de esta porque los alfabetizadores no mantienen una relación de dependencia económica con el Estado, pero sí mantienen una relación de dependencia que podría llamarse ético-política con él mismo, debido a las funciones que asumen al ser alfabetizadores.

En cierta manera, este procedimiento es un mecanismo coercitivo por parte del Estado, ya que se les impone un cierto aparato legal en donde se establece sus obligaciones, las cuales son asumidas voluntariamente.

$\diamond$ Con respecto al tema de la flexibilización habría que colocar sobre la mesa la discusión sobre las condiciones en las que se presentan las diferentes ofertas educativas destinadas a los adultos analfabetos. ¿Por qué la discusión? Porque bajo estas anteojeras de la flexibilización, que también es pertinente trasladarla al campo educativo, se orienta a la persona adulta, por ejemplo bajo la iniciativa de estos programas de alfabetización u otras ofertas, a que se vaya adaptando e incorporando a las diversas iniciativas escolares que le ofrece el sistema, logrando que se deposite básicamente la responsabilidad, tanto del éxito como del fracaso, en su accionar.

$\diamond$ Otra arista del problema es la suerte que corren estos adultos no calificados en el mercado laboral. Pueden estar sujetos a ser los integrantes permanentes de estas políticas focalizadas que se planifican y gestionan para lograr que sigan estando en el mismo lugar desde el cual partieron.

Siguiendo a Castel (1997) se puede decir que:

Los jóvenes realmente no calificados corren el peligro de no tener alternativa de empleo, puesto que los lugares a los que podrían aspirar son ocupados por otros, más calificados que ellos. Más en profundidad esta lógica corre el riesgo de invalidar las políticas que ponen énfasis en la calificación como camino real para evitar el desempleo o salir de él. Es sin duda una visión todavía optimista de la "crisis" la que lleva a pensar que, mejorando y multiplicando las calificaciones, uno se precave contra la "inempleabilidad". Es cierto que, en términos estadísticos, de la "baja calificación" derivan los mayores contingentes de desempleados. Pero esta correlación no implica una relación directa y necesaria entre calificación y empleo. La baja calificación puede llegar siempre tarde a la guerra, si mientras tanto se ha elevado el nivel general de formación (Castel, 1997: 408-409).

Para finalizar, se retoma la perspectiva de la educación que se mantiene desde una visión económica. Se dice que los recursos públicos de un país se deben concentrar en permitir el acceso de las personas pobres a los niveles básicos, y se afirma que la educación superior está fuertemente subvencionada. Los recursos destinados a la educación superior se deben trasladar a la básica con el propósito de permitir que toda la población tenga acceso a esta última (Giraldo, 2001: 69).

Con respecto a lo mencionado anteriormente el mismo organismo del Banco Mundial propulsa que los gobiernos orienten parte de su presupuesto a la educación primaria permitiendo el acceso de las personas pobres a los niveles básicos (Giraldo, 2001: 69). 


\section{CONCLUSIONES}

En el trabajo se realizó un recorrido teórico sobre las funciones principales del Estado, las características de un Estado interventor, las llamadas políticas focalizadas, a los fines de utilizarlo como un marco de referencia que permita conocer e interpretar las acciones llevadas a cabo a través de las llamadas políticas públicas focalizadas implementadas en nuestro país en estas últimas décadas.

El artículo puede ir abriendo varios interrogantes. Entre ellos: ¿Por qué el Estado fue variando sus funciones? ¿A qué fines políticos respondía? ¿Cuáles fueron los condicionamientos que permitieron la conformación del modelo de intervención del mercado? ¿Qué papel fueron adoptando los diversos actores sociales?

Las nuevas políticas han impactado en cada una de las dimensiones sociales y exigen a los integrantes de las sociedades que se adapten $y$ acomoden a las exigencias provenientes del gran concepto que detenta el poder en la actualidad: el mercado.

A pesar de los avatares de estos últimos años en cuanto al crecimiento del analfabetismo, de la pobreza, sigue siendo propicio defender $y$ conservar ciertos principios que no deberían variar de acuerdo con el tinte que adopten las políticas estatales. Entre ellos podemos mencionar fundamentalmente el derecho a la educación; con esto se quiere decir que la educación no puede mirarse a través de los ojos del mercado; ella no es un servicio como pretenden imponer los teóricos del nuevo paradigma político-económico. Sino por el contrario, debería ser el camino que permita a la población alcanzar una buena calidad de vida, entendida bajo la mirada de la dignidad de los seres humanos, dignidad que permita un adecuado bienestar $y$ un despliegue de las diferentes potencialidades.

Se estima conveniente, entonces, que como actores sociales podamos adoptar un protagonismo en la situación profesional; protagonismo que implique poder plantearnos ciertos interrogantes: ¿Qué implicancias sociales tiene mi accionar? ¿Cuáles son las posibilidades cercanas para facilitar cambios en la vida cotidiana?

\section{BIBLIOGRAFÍA}

Castel, Robert. La metamorfosis de la cuestión social. Buenos Aires. Ed. Paidós. Pág 406, 408-409. 1997.

Giraldo, César. Finanzas Públicas en América Latina: la economía política. Caps. 1 y 2. Bogotá. Ediciones desde abajo, 2001.

Lo Vuolo, R. y otros. La pobreza... de la política contra la pobreza. Capítulo 6. Madrid, Buenos Aires. Ciepp/Miño y Dávila. 1997.

Página del Ministerio de Educación, Ciencia y Tecnología de la Nación. Disponible en http://www.mect.gov [10 de mayo 2005]. 